\title{
A Comparison of the Mussel Anodonta woodiana's Acute Physiological Responses to Different Algae Diets
}

\author{
Yuxian Liu, Aimin Hao, Yasushi Iseri, Takahiro Kuba, and Zhenjia Zhang
}

\begin{abstract}
The bivalve Anodonta woodiana is widely distributed throughout Chinese freshwaters and is an important economic pearl mollusk. Recently, $A$. woodiana as a biomanipulation tool in Chinese lakes due to its strong suppression of phytoplankton, has been attracted increasingly more attention. In order to examine whether $A$. woodiana can exert grazing pressure on Microcystis and to evaluate the different effects of each algae diet on mussels' potential growth, a comparative study was carried out on the acute physiological responses to variable microalgae diets including toxic microcystin-producing cyanobacteria Microcystis aeruginosa and non-toxic green algae Scenedesmus obliquus. The values of filtration rate, absorption efficiency, oxygen consumption rate and ammonia excretion rate of $A$. woodiana were measured and finally the scope for growth (SFG) value as a measure of metabolic energy balance for $A$. woodiana was calculated and compared. The results showed that the mussel $A$. woodiana has a higher grazing ability on the toxic $M$. aeruginosa compared with the green algae $S$. obliquus; furthermore, the effects of different algae diets on SFG of $A$. woodiana demonstrated that the toxic $M$. aeruginosa may supply more energy for $A$. woodiana's potential growth. These results indicated that $A$. woodiana has strong adaptation ability when they were exposed to toxic Microcystis solution in this study, which implied that there is high application feasibility of $A$. woodiana as a toxic Microcystis-blooming controller in practice.
\end{abstract}

Index Terms-Anodonta woodiana, microcystis aeruginosa, scenedesmus obliquus, scope for growth (SFG).

\section{INTRODUCTION}

Lake Taihu is the third largest freshwater lake in China and situated in the Yangtze delta. Since 1980's, however, the development of industry and agriculture in the lake region, as well as a rapid increase in the population has resulted in pollutants being produced and discharged into rivers and the lake. With the deterioration of inflow water quality, eutrophication and cyanobacterial blooms have occurred. Recently, cyanobacterial blooms have extended its coverage and persisted throughout the summer, which affected the function of the lake as a drinking water supply [1].

Manuscript received April 13, 2013; revised July 12, 2013. This work was supported in part by the Research Institute for East Asia Environments, Kyushu University under a grant from Mitsubishi Corporation.

Y. X. Liu and T. Kuba are with the Graduate School of Engineering, Kyushu University, Fukuoka 819-0395, Japan (e-mail: axian87@ gmail.com, kuba@civil.kyushu-u.ac.jp).

A. M. Hao is with the Research Institute for East Asia Environments, Kyushu University, Fukuoka 819-0395, Japan (e-mail: hao.aimin.849@m.kyushu-u.ac.jp ).

Y. Iseri is with the West Japan Engineering Consultants, Inc., Fukuoka 810-0004, Japan (e-mail: iseri@wjec.co.jp).

Z. J. Zhang is with the Graduate School of Environmental Science and Engineering, Shanghai Jiaotong University, Shanghai 200240, China (e-mail: zjzhang@sjtu.edu.cn).
To solve cyanobacterial blooms problem and obtain normal lake ecosystem, many approaches have been applied to control growth of phytoplankton. One of the extensively used approaches is biomanipulation, using filter feeders, including zooplankton [2].

Farmed silver carp and bighead carp are the main focus of the non-traditional biomanipulation technique [3], and in recent years, more studies have been reported about the utilization of silver carp and bighead carp in managing algal community structure. However, the digestibility of algae by stomach less filer-feeding fishes has been debated [4]. Furthermore, experimental stocking of silver carp for managing phytoplankton biomass in lakes and ponds has often failed to reduce algae [5].

Other than these filter-feeding fish, bivalves are also the important consumers on phytoplankton especially when they are abundant. However, only zebra mussel (Dreissena polymorpha) has been extensively studied before. In the previous studies, the zebra mussel was found to successfully coexist with Microcystis blooms and believed to be an important biofilter for its preferential grazing on Microcystis [6].

To explore whether the mussels other than zebra mussels can exert potential grazing pressure on bloom-forming algae, we chose the mussel Anodonta woodiana, which is widely distributed throughout Chinese freshwaters and is an important native economic peal mollusk. In Lake Taihu, where Microcystis blooms frequently especially in summer, abundant $A$. woodiana can be sampled in the lakes especially in the littoral zones.

Previous studies have generally focused on the effects of bivalves on water body. Intensive $A$. woodiana has been promoted as a tool in biomanipulation of lakes in China and strong suppression of phytoplankton, apparent changes of phytoplankton community structure and the improvement of water transparency were observed [7].

However, the effects of different algae diets qualities on the physiological responses of the bivalve $A$. woodiana, that integrates all the physiological processes, including feeding activity like filtration and absorption, metabolism like respiration and ammonia excretion and ultimately energy balance, known as scope for growth (SFG), have not been considered yet.

The SFG measurement, which measures the energy available for growth, has been widely used in many ecotoxicological studies [8].

This measurement of physiological energetics, normally in terms of SFG, can provide instantaneous assessment of the growth process of bivalves as affected by environmental stress and pollution. SFG is measured by integrating several physiological parameters, including filtration rate, absorption 
efficiency, respiration rate and ammonia excretion rate, all of which can directly affect the energy available for growth, maintenance and reproduction of bivalves.

Although this physiological biomarker has been widely applied in assessing the physiological condition of bivalves, there is no study that applied this biomarker to determine the effects of different algae diets qualities on freshwater bivalves.

Therefore, the aim of this study is to examine the most popular native mussel $A$. woodiana can exert grazing pressure on Microcystis and to introduce SFG related to energetic balance of $A$. woodiana to evaluate the influence of different diets including toxic (microcystin-producing cyanobacteria Microcystis aeruginosa) and non-toxic (green algae Scenedesmus obliquus) on mussels' potential growth. The results obtained may lead to a better understanding of the feeding selective mechanism of $A$. woodiana, which are relevant for studies of high efficiency culture, as well as for the possible application of this bivalve in biomanipulation as toxic cyanobacterial blooms controller in turbid shallow lakes.

\section{MAterials AND METHODS}

\section{A. Production of Algal Species}

Due to the fact that Microcystis aeruginosa is the common dominant species in the blooms, toxic strain of Microcystis is used as the food fed to the mussels. Scenedesmus obliquus is also the food fed in the experiments as a comparison.

Toxic $M$. aeruginosa strain NIES-90 and green algae $S$. obliquus strain NIES-2279 were obtained from National Institute for Environmental Studies, Ibaraki in Japan. Both algal species were cultured under controlled conditions $\left(25{ }^{\circ} \mathrm{C} ; 12 \mathrm{~h}\right.$ light:dark cycle). Each strain was used in its exponential stable phase of growth.

Cultured algae were separated from culture medium by centrifugation and they were diluted in aerated dechlorinated tap water. In order to obtain comparable masses of suspended matter in each diet, the initial Chl.a concentration were corresponding to around $35 \mu \mathrm{g} \cdot \mathrm{L}^{-1}$ in the food treatments. There were three food treatments: (1) toxic M. aeruginosa (2) S. obliquus (3) a mixture of $50 \%$ toxic $M$. aeruginosa and $50 \%$ S. obliquus.

The characteristics of algae diets were listed in Table I. The bivalves of $A$. woodiana were supplied by Gunma Prefecture in Japan. The bivalves were kept at $4^{\circ} \mathrm{C}$ before transporting them to the laboratory. Immediately upon arrival, the bivalves were transferred to $35 \mathrm{~L}$ aquaria with $20 \mathrm{~L}$ aerated dechlorinated tap water at controlled temperature $25^{\circ} \mathrm{C}$, under a light:dark regime of $12 \mathrm{~h}: 12 \mathrm{~h}$ for at least one week, before being used for experiments. The water was completely refreshed three times per week.

\section{B. SFG Measurement}

Grazing experiments of $A$. woodiana were performed with two mussels in each of three replicates in a beaker containing $2,000 \mathrm{~mL}$ of experimental food solution with constant aeration. Beakers with food, but without mussels, were used as a control to check for growth of phytoplankton cells during the experiments. The beakers were placed in an incubator at $25 \pm 0.5^{\circ} \mathrm{C}$.

Mussels (shell length of $9.13 \pm 0.32 \mathrm{~cm}$ and fresh-weight of $79.63 \pm 8.69 \mathrm{~g}$ ) were chosen with similar sizes to remove the effects caused by physiological sizes.

Before introduction to the beakers, bivalves were gently cleaned with a brush under running de-ionized water to remove phytoplankton adhered to the shell and not fed for 2 days in clean aerated dechlorinated tap water to clear the guts. After fed with different algae diets for four hours, the SFG in bivalves were quantified fed with each food solution for treatment microcosms.

\section{Filtration Rate Measurement}

The filtration rate $\left(\mathrm{FR}, \mathrm{mL} \cdot \mathrm{g}^{-1} \mathrm{FW} \cdot \mathrm{h}^{-1}\right)$ of each individual bivalve, defined as the volume of water cleared per unit time was determined by the time course of the decrease of algal density due to bivalve filtration. The experiment began when the shell valve of the bivalve opened. Chl.a concentration in the feeding beaker was measured every one hour, for a total of 4 hours.

The algae solution was stirring gently to keep food in suspension and homogeneous. Each time suspended food was sampled at certain intervals of time. The Chl.a concentration was measured by fluophotometer, and FR was determined by the following formula, which has been used in modified form by many other authors [9]:

$$
F R=(V /[w t]) \operatorname{Ln}\left[C_{0} / C_{t}\right]
$$

In which $V$ is the volume of the food suspension $(2 \mathrm{~L}), w$ the fresh weight of the mussels in each vessel $(\mathrm{g}), t$ the duration of the experiment (in hour), $C_{0}$ is the Chl.a concentration $\left(\mu \mathrm{g} \cdot \mathrm{L}^{-1}\right)$ at 0 or one time step before $\mathrm{t}$ and $C_{t}$ is the algae concentration at time $t$. In the vessels with mussels the algae concentration was corrected for changes observed in the control vessels.

The amount of ingested or consumed energy (C) was calculated for each individual by multiplying FR by the amount of particle organic material (POM) per liter in input water samples and assuming an energy content of algal material of water samples and assuming an energy content of algal material of $23 \mathrm{~J} \cdot \mathrm{mg}^{-1}[10]$.

\section{Respiration Rate Measurement}

The respiration rate $\left(\mu \mathrm{gO}_{2} \cdot \mathrm{g}^{-1} \cdot \mathrm{h}^{-1}\right)$ of bivalves was measured by respirometers in enclosed chambers $(1,200 \mathrm{~mL})$ full of oxygen saturated tap water after filtration rate measurement experiments. The bivalves were isolated from the treatment vessels after the filtration rate measurement and transferred into corresponding enclosed chambers. A chamber without a bivalve was used as a control. Tap water in the chamber was mixed by a magnetic stirrer placed on the bottom. The oxygen concentration in the solution was detected by an oxygen electrode. Measurement of oxygen concentration commenced when the animals opened their shell valves and lasted for 2 hours in darkness. Oxygen concentration was plotted against time of measurement and respiration rate was calculated from the slope of the decrease 
of oxygen concentration over time during two hours. The amount of energy used in respiration (R) was calculated assuming an energy content of $0.456 \mathrm{~J} \cdot \mu_{\mathrm{mol}}{ }^{-1} \mathrm{O}_{2}[11]$.

\section{E. Absorption Efficiency Measurement}

The absorption efficiency of the organic matter by mussels was determined by the ratio method [12]. This method assumed that the absorption of the inorganic component of food was insignificant during the digestive process. After the respiration rate measurement, the bivalves were placed into three vessels with $2 \mathrm{~L}$ aerated dechlorinated tap water. Any feces egested were collected after 12 hours. The feces were filtered onto a preweighted $\mathrm{GF} / \mathrm{F}$ filter (Whatman). The filters were subsequently ashed in a muffle furnace at $450^{\circ} \mathrm{C}$ for $1 \mathrm{~h}$, and the loss of organic matter was calculated. The absorption efficiency (AE) was calculated by comparing the ratio of organic and inorganic materials between the food and feces, by the following equation [12]:

$$
A E(\%)=(F-E) /[(1-E) \times F] \times 100
$$

where $F$ is the ash-free dry weight:dry weight ratio (AFDW/DW) of the food and $E$ is the ash-free dry weight: dry weight ratio of feces.

\section{F. Excretion Rate}

Another component of metabolic loss is presented by the products of excretion. The excretion rate (ER; $\mathrm{mg} \mathrm{NH}_{4}{ }^{+}-\mathrm{N} \cdot \mathrm{h}^{-1}$ ) measurement was performed simultaneously with the filtration rate measurement. After the collection of Chl.a with $\mathrm{GF} / \mathrm{C}$ filter paper (Whatman), the filtered water samples were measured for ammonium ion concentration with Ion Chromatography ICS-2100_ICS-1100_AS. Ammonium ion concentration was plotted against time of measurement and excretion rate was calculated from the slope of the decrease of ammonium ion concentration over time (ammonium ion concentration was measured every 30 minutes). The amount of energy used in excretion (U) was calculated for each individual by multiplying ER by assuming an energy content ammonium ion of $19.4 \mathrm{~J} \cdot \mathrm{mg}^{-1} \mathrm{NH}_{4}^{+}[10]$.

\section{G. Calculation of $S F G$}

The SFG, which defined the energy available for growth and reproduction and was calculated by the following equation [10]:

$$
\mathrm{SFG}=\mathrm{C} \times \mathrm{AE}-\mathrm{R}-\mathrm{U}
$$

where $\mathrm{C}$ is the consumed energy, $\mathrm{AE}$ is absorption efficiency, $\mathrm{R}$ is respired energy, and $\mathrm{U}$ is excreted energy.

\section{H. Statistic Analysis}

For all feeding data, physiological parameters were compared using one-way analysis of variance (ANOVA). All statistical analysis was carried out with Excel.

\section{RESULtS}

\section{A. Characteristics of Diets}

Chl.a concentrations were adjusted to approximately 35 $\mu \mathrm{g} \cdot \mathrm{L}^{-1}$ for the three diets tested (Table I; range: 30.4-38.7 $\left.\mu \mathrm{g} \cdot \mathrm{L}^{-1}\right)$, but there were not significant variations between diets (one-way ANOVA, $\mathrm{F}<\mathrm{F}_{0.05}$ ). POM concentrations did not differ statistically (range: $105-120 \mathrm{mg} \cdot \mathrm{L}^{-1}$; one-way ANOVA, $\mathrm{F}<\mathrm{F}_{0.05}$ ). An organic content between 93.6-95.6\% was obtained for the three diets (Table I) and no significant differences were observed between them (ANOVA on arcsine transformed data, $\mathrm{F}<\mathrm{F}_{0.05}$ ). Size spectra obtained with the microscope showed that $S$. obliquus was obviously larger than $M$. aeruginosa.

Microscope observations showed that the stain $M$. aeruginosa NIES-90 consisted of single cell suspensions, while S. obliquus NIES-2279 consisted of colonies.

\section{B. Acute Physiological Responses on Different Diets}

\section{1) Grazing on different algae diets}

The weight-specific filtration rate and absorption efficiency of $A$. woodiana on each diet solution are shown in Fig. 1. A comparison of the mean filtration rate (FR) calculated with the three diets offered to mussels showed a significant statistical difference (Fig. 1, one-way ANOVA, $\mathrm{F}>\mathrm{F}_{0.05}$ ) ranging from $6.03 \mathrm{~mL} \cdot \mathrm{g}^{-1} \mathrm{FW} \cdot \mathrm{h}^{-1}$ for $S$. obliquus NIES-2279 to $14.38 \mathrm{~mL} \cdot \mathrm{g}^{-1} \mathrm{FW} \cdot \mathrm{h}^{-1}$ for the mixture diet.

Mean absorption efficiency was significantly higher for mussels fed on the algae $M$. aeruginosa $(88.95 \%)$ than those fed either on the mixture diet, or S. obliquus $(40.89 \%$ and $38.46 \%$, respectively) (one-way ANOVA, F $>\mathrm{F}_{0.05}$, Fig. 1).

\begin{tabular}{|c|c|c|c|c|c|c|c|}
\hline Strain code & Shape & Origion & $\operatorname{ESD}(\mu \mathrm{m})$ & Microcystin $\left(\mu \mathrm{g} \cdot \mathrm{L}^{-1}\right)$ & Chl.a $\left(\mu \mathrm{g} \cdot \mathrm{L}^{-1}\right)$ & $\mathrm{POM}\left(\mathrm{mg} \cdot \mathrm{L}^{-1}\right)$ & Organic content $(\%)$ \\
\hline Microcystis aeruginosa NIES-90 & Single cell & $\begin{array}{l}\text { National Institute for } \\
\text { Environmental Studies, Ibaraki, } \\
\text { Japan }\end{array}$ & $3.0-4.5^{33}$ & 1.5 & 38.7 & 120.0 & 95.6 \\
\hline Scenedesmus obliquus NIES-2279 & Colony & $\begin{array}{l}\text { National Institute for } \\
\text { Environmental Studies, Ibaraki, } \\
\text { Japan }\end{array}$ & $9.1-18.1^{34}$ & No microcystin & 30.4 & 105.0 & 93.6 \\
\hline Mixture & Colony & $\begin{array}{c}\text { National Institute for } \\
\text { Environmental Studies, Ibaraki, } \\
\text { Japan } \\
\end{array}$ & - & 0.8 & 37.0 & 112.5 & 94.9 \\
\hline
\end{tabular}

TABLE I: CHARACTERISTICS OF THE EXPERIMENTAL DIETS FED TO $A$. WOODIANA

POM: particulate organic matter; ESD: equivalent spherical diameter. Number of measurement=3. 


\section{2) Metabolic rates on different algae diets}

The metabolic rates of A. woodiana feeding on different diets were shown in Fig. 2.

A comparison of the three metabolic rates indicator, respiration rate, amongst the three different diets were significantly statistically different (Fig. 2, one-way ANOVA, $\left.\mathrm{F}>\mathrm{F}_{0.05}\right)$. Mean respiration rates of the mussels fed with mixture diet were observed significantly higher than those fed with each of the single diet. Meanwhile, the respiration rates of bivalves fed with $M$. aeruginosa was obviously higher than those fed with $S$. obliquus. Mean values of respiration rates ranged from $2.66 \mu \mathrm{gO}_{2} \cdot \mathrm{g}^{-1} \mathrm{FW} \cdot \mathrm{h}^{-1}$ for $S$. obliquus to $14.37 \mu \mathrm{gO}_{2} \cdot \mathrm{g}^{-1} \mathrm{FW} \cdot \mathrm{h}^{-1}$ for the mixed food.

Ammonia excretion rates among bivalves fed with each diet were not obviously different (Fig. 2, one-way ANOVA, $\left.\mathrm{F}<\mathrm{F}_{0.05}\right)$. Furthermore, as shown in Fig. 2, mean values of ammonia excretion rates ranged from $0.69 \mu \mathrm{gNH}_{4}{ }^{+} \cdot \mathrm{g}^{-1} \mathrm{FW} \cdot \mathrm{h}^{-1}$ for the food M. aeruginosa to $1.11 \mu \mathrm{gNH}_{4}^{+} \cdot \mathrm{g}^{-1} \mathrm{FW} \cdot \mathrm{h}^{-1}$ for the mixed food.

\section{Impacts of Different Algae Diets on SFG of A. woodiana}

The energy equivalents of mussels are presented in Table II. The energy used for growth as represented in SFG, differed significantly among the three algae diets (one-way ANOVA, $\mathrm{F}>\mathrm{F}_{0.05}$ ), ranging from $5.90 \mathrm{~J}^{-1} \mathrm{~g}^{-1} \mathrm{~h}^{-1}$ for $S$. obliquus to $27.16 \mathrm{Jgg}^{-1} \cdot \mathrm{h}^{-1}$ for $M$. aeruginosa. SFG in mussels was significantly higher for the bivalves fed with $M$. aeruginosa than those fed with the other two diets, mainly contributed by the highest filtration rates.

\section{Discussion}

\section{A. Characteristics of Diets}

As for many freshwater and marine suspension feeders, feeding-process of zebra mussels are influenced by environmental factors such as temperature [13], but also by food quality and food quantity. In this study, $A$. woodiana were fed three algal diets with different characteristics.

In the case of algal suspensions, food quantity can be expressed as Chl.a concentration and particulate organic matter (POM). Each diet was supplied to the mussels at comparable levels of POM in order to eliminate any effect of food quantity on bivalves' physiological parameters. Furthermore, each algae suspension was offered at bloom levels corresponding to approximately $30 \mu \mathrm{g} \cdot \mathrm{L}^{-1}$ of Chl.a, which is in the middle of the range of values found in Lake Taihu.

Food quality can be expressed in different ways: organic: inorganic ratio of seston, toxin content and also polyunsaturated fatty acids (PUFAs) content. The shape and size of algal cells are also parameters that potentially affect the feeding behavior of zebra mussels.

For all the three diets tested, organic content was high (higher than $90 \%$ ), corresponding to an organic:inorganic ratio of about 9:1 and not significantly different between diets. According to Schneider et al. [14], with such a high organic content, zebra mussels reported with high feeding parameters, particularly high absorption efficiency and high SFG. Two of the three algal suspensions contained toxins, has a MCs in a concentration of $1.5 \mu \mathrm{g} \cdot \mathrm{L}^{-1}$ and the other contains MCs with a concentration of $0.8 \mu \mathrm{g} \cdot \mathrm{L}^{-1}$. The three diets has different shapes and sizes, S. obliqure presenting the largest cell type in the form of cell colonies, and the strain of M. aeruginosa corresponds to the smallest cell type. Analysis of each diet's characteristics therefore shows that the predominant factor that could influence the mussel's feeding behaviour was food quality, particularly toxicity, and cell shape and size. Our toxin measurement using enzyme-linked immunosorbent assay (ELISA) method did not allow separate quantification of MC-LR or MC-LF but gives a total estimation of MCs present in cyanobacterial cells. Therefore, in our experiments, the impacts of MCs on the mussels' feeding behaviour may be the result of a combined effect of the toxins present in both variances.

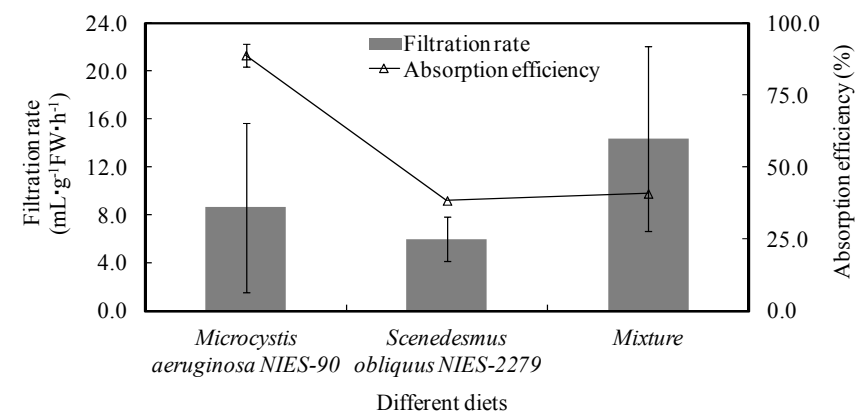

Fig. 1. The filtration rate and absorption efficiency of $A$. woodiana feeding on different diets. Error bars are S.E. $(n=3)$.

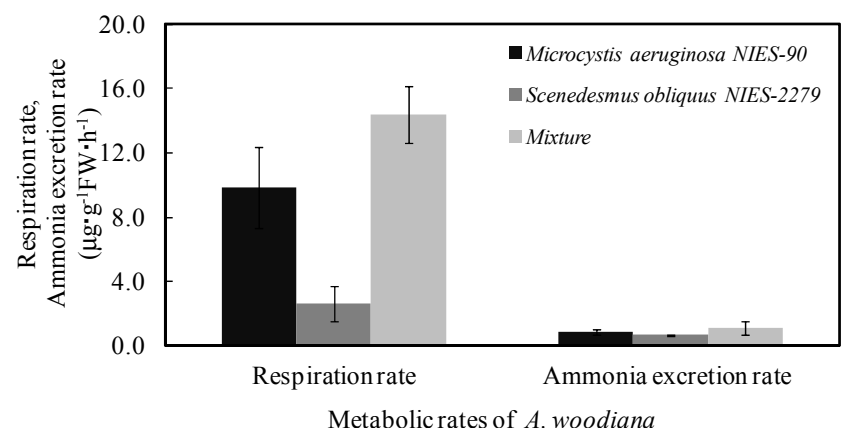

Fig. 2. The metabolic rates of $A$. woodiana feeding on different diets. Error bars are S.E. $(n=3)$.

TABLE II: ENERGy EQUiVALENT OF THE PHySIOLOGICAL RESPONSES OF $A$. WOODIANA ON DIFFERENT DIETS

\begin{tabular}{ccccc}
\hline \hline Strain code & $\mathrm{A}\left(\mathrm{J} \cdot \mathrm{g}^{-1} \cdot \mathrm{h}^{-1}\right)$ & $\mathrm{R}\left(\mathrm{J} \cdot \mathrm{g}^{-1} \cdot \mathrm{h}^{-1}\right)$ & $\mathrm{U}\left(\mathrm{J} \cdot \mathrm{g}^{-1} \cdot \mathrm{h}^{-1}\right)$ & $\mathrm{SFG}\left(\mathrm{J} \cdot \mathrm{g}^{-1} \cdot \mathrm{h}^{-1}\right)$ \\
\hline Microcystis aeruginosa NIES-90 & 27.34 & 0.14 & 0.02 & 27.16 \\
Scenedesmus obliquus NIES-2279 & 5.94 & 0.04 & 0.01 & 5.90 \\
Mixture & 8.25 & 0.20 & 0.02 & 8.03 \\
\hline \hline
\end{tabular}

Moreover, no reports are available in the literature concerning the lipopolysaccharides content of these algae diets. Furthermore, temperature conditions and the dose of food supplied met the requirement for a high feeding response.

\section{B. Acute Physiological Responses on Different Diets}

\section{1) Filtration rates}

As shown in Fig. 1, the weight-specific filtration rate of $A$. woodiana values obtained in this study fell within the range 
of values found by Yang et al. [7].

In this study, the filtration rates of the mussel $A$. woodiana were significantly higher in the mixed food treatment than those in single food treatments. This is in accordance of the findings of Ying Liu et al. [15] who observed higher filtration rates of the mussels Unio douglasiae and Corbicula fluminea on a mixture of S. obliquus and toxic M. aeruginosa than the single food alone. Dionisio Pires et al. [16] also observed a higher filtration rate of zebra mussel on a mixture of S. obliquus and M. aeruginosa alone.

It was proposed by Vanderploeg et al. [17] that the sensory quality of the food may affect the feeding activity of the mussels and hence their pumping rate. Thus, it can be suspected that the sensory impact of mixed $S$. obliquus and $M$. aeruginosa on the mussels might be greater than that of $S$. obliquus or M. aeruginosa alone, thus resulting in higher pumping and clearance rate in the mixed food treatment.

Furthermore, it was noted that clearance rates obtained with the green algae $S$. obliquus, which is considered as highly desirable food algae was much lower than them obtained with $M$. aeruginosa. Mussel's filtration gill selection is mainly affected by algae sizes. As the algae diets characteristics of size spectra obtained with the microscope showed that $S$. obliquus was obviously larger than $M$. aeruginosa. M. aeruginosa used here are single cells (cells range from 2.61 to $5.40 \mu \mathrm{m}$ in diameter) instead of the colonies in natural water body; S. obliquus is colonial green alga consisting of cells aligned in a flat plate. It is probably that $M$. aeruginosa cells were in the range $A$. woodiana's gill preferred.

In addition, this indicates that the toxic $M$. aeruginosa in this did not exert acute effects on the grazing of $A$. woodiana in present research and on Unio douglasiae in previous research [15]. When very toxic Microcystis contained predominately MC-LF, which is known to be one of the most potent $\mathrm{MC}$ variants was supplied in the algae suspension at high levels, caused the mussels to reduce their filtration rate significantly. Thus, it can be explained that in the present study, the MC-LF concentration in the algae suspension maybe not sufficient to induce the negative effect on mussels' filtration rate.

\section{2) Absorption rates}

In this study the absorption rates of $A$. woodiana on $M$. aeruginosa were obviously higher that the values obtained by $A$. woodiana on $S$. obliquus and the mixed diets. This was similar to the results reported by Ying Liu et al. [15]. In their study, it was also found that both the mussels Unio douglasiae and Corbicula fluminea excreted more $S$. obliquus cells than $M$. aeruginosa cells in the excreted produces thus both the mussels they used preferred to ingest M. aeruginosa cells to $S$. obliquus. Meanwhile, they gave the possible reason was that $S$. obliquus cells have thick cell walls which makes them indigestible in the digestive tracks. Previous studies report that zebra mussels showed a preference for the low-toxicity strain Microcystis aeruginosa CCAP1450/06 contained $7.4 \mu \mathrm{g} \cdot \mathrm{L}^{-1}$ of the MC-LR variant to the green algae Chlorella vulgaris. However, we inferred that it is the different digestive enzyme activity in $A$. woodiana's digestive tract that induced the prefer ingestion of M. aeruginosa to the green algae. As it was reported by Zhiliang Fei et al. [18] that the ratio of amylase to protease enzyme activities (A/P) in the stomach of $A$. woodiana was quite high, which indicated that $A$. woodiana has stronger digestive ability on cyanobacteria that mainly contains of starch than green algae that mainly contains of protein. In a word, the toxic $M$. aeruginosa did not exert effects on the grazing of $A$. woodiana in present research, on the contrary $A$. woodiana preferred to graze on the toxic $M$. aeruginosa to the green algae $S$. obliquus.

\section{Impacts of Different Algae Diets on SFG of A. woodiana}

As the endpoint of these experiments, the net energy balance (SFG) was calculated and indicated the $M$. aeruginosa as diet supplied the mussel with the highest SFG value compared with either $S$. obliquus or the mixture diet. Furthermore, the least SFG value supplied by the S. obliquus as the diet was mainly due to the significant production of 'pseudodiarrhoea', which is pseudofaecal material known to be rich in mucus [19]. Since molluscan mucus is known to be expensive to produce.

In addition, as it is reported by Welch [20], the ratio of SFG to A (named net growth efficiency $\mathrm{K}_{2}$ ) may range from $20 \%$ to $90 \%$; High $\mathrm{K}_{2}$-value must also be looked upon as an adaptive response to environmental conditions; growth efficiencies under laboratory conditions are often higher than in the field. However, as shown in Table II, the SFG value measured in this study were over $90 \%$ of the A value. One possible reason for the much lower consumed energy by respiration and ammonium excretion is that respiration rate and ammonium excretion rate measured here were standard metabolic rates without food which are lower than active metabolism rates.

Ultimately, the toxic $M$. aeruginosa did not restrain the grazing behaviour of $A$. woodiana instead supplied the highest SFG value for the mussels' growth. In some degree, this indicated that the mussel $A$. woodiana accumulated and depurated MCs, although, we could not distinguish whether it was MC-LR or the MC-LF variant. Further experimentations could be needed to investigate this assumption.

As an instantaneous measurement of the energy available for growth, increased SFG indicates that the processing of $M$. aeruginosa by the bivalves $A$. woodiana is a profitable mechanism as a large amount of energy was recovered by $A$. woodiana feeding on the M. aeruginosa.

\section{CONCLUSION}

The acute physiological responses on different diets by $A$. woodiana indicated that the mussel $A$. woodiana preferred to graze on the toxic $M$. aeruginosa compared with the green algae $S$. obliquus.

In addition, the impacts of different algae diets on SFG of $A$. woodiana demonstrated that the toxic $M$. aeruginosa supplied much energy for $A$. woodiana's potential growth. On the other hand, A. woodiana showed strong adaptation ability exposed to toxic M. aeruginosa solution.

Therefore, the results in this study indicated that there is 
quite high feasibility to use $A$. woodiana as a toxic Microcystis-blooming controller in the practice.

\section{ACKNOWLEDGMENT}

I would like to thank Mr. Hiroshi SAKAI from Tokyo University for the microcystin measurement.

\section{REFERENCES}

[1] B. Q. Qin, P. Z. Xu, Q. L. Wu, L. C. Luo, and Y. L. Zhang, "Environmental issues of Lake Taihu, China," Hydrobiologia, vol. 581, pp. 3-14, 2007.

[2] T. N. Gerasimova and P. I. Pogozhev, "Reduction of the trophic status of a water body with the use of large-size zooplankton," Water Research, vol. 29, pp. 450-459, 2002.

[3] P. Xie and J. K. Liu, "Practical success of biomanipulation using filter-feeding fish to control cyanobacterial blooms: a synthesis of decades of research and application in a subtropical hypereutrophic lake," Scicentific World, vol. 1, pp. 337-356, 2001.

[4] P. Xie, "Gut contents of silver carp, Hypophthalmichthys molitrix, and the disruption of a centric diatom, Cyclotella, on passage through the esophagus and intestine," Aquaculture, vol. 180, pp. 295-305, 1999.

[5] E. A. Laws and R. S. J. Weisburd, "Use of silver carp to control algal biomass in aquatic ponds," The Progressive Fish-Culturist, vol. 52, no. 1, pp. 1-8, 1990 .

[6] N. F. Caraco, J. J. Cole, P. A. Raymond, D. L. Strayer, M. L. Pace et al., "Zebra mussel invasion in a large, turbid river: phytoplankton response to increased grazing," Ecology, vol. 78, pp. 588-602, 1997.

[7] D. M. Yang, Y.W. Chen, Z.W. Liu, and Q. L. Wu, "Top-down effects of Anodonta woodiana on the nutrient concentration and phytoplankton community composition in a microcosm ecosystem," Lake Sciences, vol. 20, no. 2, pp. 228-234, 2008 (in Chinese).

[8] J. Widdows, P. Donkin, M. D. Brinsley, S.V. Evans, P.N. Salkeld et al., "Scope for growth and contaminant levels in North Sea Mussels Mytilus edulis," Marine Ecology Progress Series, vol. 127, pp. 131-148, 1995

[9] J. Coughlan, "The estimation of filtering rate from the clearance of suspension," Marine Biology, vol. 2, pp. 356-358, 1969.

[10] J. Widdows and D. Johnson, "Physiological energetics of Mytilus edulis: scope for growth," Marine Ecology Progress Series, vol. 46, pp. 113-121, 1988.

[11] E. Gnaiger, "Heat dissipation and energetic efficiency in anima anoxibiosis: economy contra power," The Journal of Experimental Zoology, vol. 228, pp. 471-490, 1983.

[12] R. J. Conover, "Assimilation of organic matter by zooplankton," Limnology and Oceanography, vol. 11, pp. 338-345, 1966.
[13] B. L. Bayne, J. Widdows, and C. Worrall, "Some temperature relationships in the physiology of two ecologically distinct bivalve populations," in Physiological Responses of Marine Biota to Pollutants, F. J. Vern-berg, A. Calabrese, F. P. Thurberg, and W. B. Vernberg, Ed. New York: Academic Press, 1977, pp. 379-400.

[14] D. W. Schneider, S. P. Madon, J. A. Stoeckel, and R. E. Sparks, "Seston quality controls zebra mussel (Dreissena polymorpha) energetics in turbid rivers," Oecologia, vol. 117, pp. 331-341, 1998.

[15] Y. Liu, P. Xie, and X. P. Wu, "Grazing on toxic and non-toxic Microcystis aeruginosa PCC7820 by Unio douglasiae and Corbicula fluminea," Limnology, vol. 10, pp. 1-5, 2009.

[16] L. M. Dionisio Pires, R. R. Jonker, E. Van Donk, and H. J. Laanbroek, "Selective grazing by adults and larvae of the zebra mussel (Dreissena polymorpha (Pallas): application of flow cytometry to natural seston," Freshwater Biolology, vol. 49, pp. 116-126, 2004.

[17] H. A. Vanderpoleg, J. R. Liebig, W.W. Carmichael, M. A. Agy, T. H. Johengen et al., "Zebra mussel (Dreissena polymorpha) selective filtration promoted toxic Microcystis blooms in Saginaw Bay (Lake Huron) and Lake Erie," Canadian Journal of Fisheries and Aquatic Sciences, vol. 58, pp. 1208-1221, 2001.

[18] Z. L. Fei, H. Qiao, C. Hao, Z. WANG, and C. Huang, "Primary study on the digestive enzyme activities of three limnetic mussels," Freshwater Fisheries, vol. 36, no. 4, pp. 3-6, 2006 (in Chinese).

[19] G. Juhel, J. Davenport, J. O’Halloran, S. Culloty, R. Ramsay et al., "Pseudodiarrhoea in zebra mussels Dreissena polymorpha (Pallas) exposed to microcystins," The Journal of Experimental Biology, vol. 209, pp. 810-816, 2006.

[20] E. W. Harold, "Relationships between assimilation efficiencies and growth efficiencies for aquatic consumers," Ecology, vol. 49, no. 4, pp. 755-799, 1968.

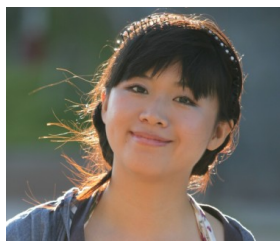

Yuxian Liu is a $\mathrm{PhD}$ student in Kyushu University. I was born in Shandong Province, China on January $4^{\text {th }}, 1987$. Now she is in the $\mathrm{PhD}$ second year in the Graduate School of Engineering. Here is my educational background:

From September, 2005 to June, 2009, she was studying in the major of Urban and Rural Planning and Resources Management, Water Resources and Hydrology Colledge in Hohai University, and got the bachelor degree; from September, 2009, she has been studying in the lab of Urban and Environmental Engineering, the Gradúate School of Engineering in Kyushu University; and will get my PhD degree in September, 2014.

As a $\mathrm{PhD}$ student, her research title is physiological responses and application feasibility of bivalves as a biomanipulation tool in Lake Taihu. 